\title{
Amygdalectomized rats can learn the classically conditioned fear response: A preliminary report
}

\author{
MELVIN L. GOLDSTEIN \\ Indiana University at Kokomo, 2300 S. Washington St., Kokomo, Indiana 46901
}

\begin{abstract}
Amygdalectomized rats can learn the classically conditioned fear response if a discriminative cue is included in the test situation; i.e., if they are run from a white background (shock compartment) to a black background (safe compartment). When the lesioned rats are run from a black shock compartment to a black safe compartment, there is a greater performance deficit. The amount of fear reduction in the test situation is probably a more important variable than the amygdalectomy in contributing to performance of the classically conditioned fear response. The integrity of the amygdaloid complex is probably not essential for the learning processes involved in classical fear conditioning. Other areas of the brain, such as the hippocampus, may be more directly involved in the acquisition and retention of classical fear conditioning and avoidance conditioning.
\end{abstract}

Brady, Schreiner, Geller, and Kling (1954) have reported acquisition deficits in amygdalectomized cats trained in the active avoidance conditioning situation. The response measure used was the number of training trials required to reach criterion. Horvath (1963) replicated these findings for a complex two-way active avoidance shuttle response. The cats were required to jump back to the place where they had been shocked, so that there was no consistent "safe" compartment in the experiment. Horvath (1963) also demonstrated that simplifying the problem by requiring the animals to jump in only one direction, from shock to a safe compartment, facilitated learning of the avoidance task. Amygdalectomized cats, therefore, could not learn a complex, two-way active avoidance response but were able to learn a simple, one-way active avoidance response.

King (1958) reported longer response latencies for amygdalectomized rats than for normals when they were trained in the two-way active avoidance shuttle response. Robinson (1963), using a modified Miller (1948) acquired drive test, also reported a learning deficit resulting from amygdalectomy in rats. Goldstein (1974) has recently shown that amygdalectomized rats could not learn the classically conditioned fear response when the conditioning and safe compartments were of the same brightness.

The specific procedural details of avoidance conditioning seem to be important determiners of the magnitude of the postoperative deficit. Horvath (1963) concluded that if the avoidance problem were

Preparation of this report was supported, in part, by a supply grant awarded by the Indiana University Office of Research and Advanced Studies (Grant No. 26-631-32). A portion of this report was written at Harbor Village, Hyannis Port, Massachusetts. The writer wishes to express his appreciation to his wife Daidee for helpful comments during the preparation of this report. Patricia Ward typed the manuscript. made relatively simple by requiring the animals to jump in only one direction, an intact amygdala was not essential for learning the avoidance response. If the problem were made more complex, however, by requiring the animals to shuttle from one "shock" compartment to another, the basolateral amygdaloid nuclei played an essential role in the learning process. McCleary (1966), citing Ursin (1965), has suggested that removing amygdalectomized cats from the shock apparatus by hand, rather than the relative simplicity of the avoidance conditioning task itself, may reduce the avoidance deficit. In any case, McCleary (1966) suggests that "enhancing the approach-avoidance conflict in an avoidance test appears to heighten its sensitivity to the post-operative deficit." Horvath's (1963) shuttle avoidance task apparently generated an approach-avoidance conflict in his animals.

A series of pilot experiments currently in progress explores the hypothesis that the effect of amygdalectomy on acquisition of the classically conditioned fear response depends to some extent on the level of difficulty of the test situation. The magnitude of the performance deficit resulting from amygdalectomy probably does not depend entirely upon the fact that a part of the brain which is important in the learning of fear-motivated behaviors has been removed but depends, also, upon the cue characteristics of the test situation. The performance deficit resulting from amygdalectomy can be counteracted, and to some extent minimized by making the test situation relatively simple from a perceptual standpoint, i.e., by including a discriminative cue in the test situation.

Preliminary results indicate that amygdalectomized rats $(N=2$ /group $)$ can learn the classically conditioned fear response if the discriminative cue is included, i.e., if they are run from a white background (shock compartment) to a black background (safe compartment). Under these 
conditions, the amount of fear reduction in the test situation is high. When the amount of fear reduction in the test situation is low, i.e., when the rats are run from a black shock compartment to a black safe compartment, there is a greater performance deficit. The performance of amygdalectomized rats can, therefore, be improved by introducing a discriminative cue into the test situation. The amount of fear reduction in the test situation is probably a more important variable than the amygdalectomy in contributing to performance of the classically conditioned fear response.

The tentative conclusion to be reached from these pilot experiments is that the integrity of the amygdaloid complex is probably not essential for the learning processes involved in classical fear conditioning. Other areas of the brain, such as the hippocampus, may be more directly involved in the acquisition and retention of classical fear conditioning and avoidance conditioning. The amygdaloid complex may be essential for the temporary motivational processes involved in fear conditioning and avoidance conditioning, and the hippocampus may be important in the more permanent processes, such as short-term memory or retention (Uretsky \& McCleary, 1969).

This hypothesis may be tested by determining whether permanent acquisition and retention deficits can be demonstrated in hippocampectomized rats under the conditions most conducive to maximal performance of the classically conditioned fear response, i.e., with the addition of the discriminative cue. Demonstration of permanent acquisition and retention deficits in such a preparation would suggest that the hippocampus rather than the amygdaloid complex is the significant structure in the acquisition and retention of a classically conditioned fear response.

Additional studies are needed to determine the effect of the addition of the discriminative cue on tests of retention in amygdalectomized rats. Goldstein (1974) has recently reported a retention deficit in amygdalectomized rats, but the test situation did not contain the discriminative cue. It is quite possible that addition of the discriminative cue during the retention test will minimize the retention deficit found in amygdalectomized rats. Such a result would further support the notion that the amygdaloid complex is not essential for the learning or retention of the classically conditioned fear response.

\section{REFERENCES}

Brady, J. V., Schreiner, L., Geller, I., \& Kling, A. Subcortical mechanisms in emotional behavior: The effect of Rhinencephalic injury upon the acquisition and retention of a conditioned avoidance response in cats. Journal of Comparative and Physiological Psychology, 1954, 47, 179-186.

Goldstein, M. L. The effect of amygdalectomy on acquisition of a classically conditioned fear response. Bulletin of the Psychonomic Society, 1974, 4, 465-466.

Goldstein, M. L. The effect of amygdalectomy on long-term retention of an undertrained classically conditioned fear response. Bulletin of the Psychonomic Society, 1974, 4, 548-550.

Horvath, F. E. Effect of basolateral amygdalectomy on three types of avoidance behavior in cats. Journal of comparative and physiological psychology, 1963, 56, 380-389.

KING, F. A. Effects of septal and amygdaloid lesions on emotional behavior and conditioned avoidance responses in the rat. Journal of Nervous and Mental Diseases, 1958, 126, 57-63.

McCleary, R. A. Response-modulating functions of the limbic system: Initiation and suppression. In E. Stellar \& J. M. Sprague (Eds.), Progress in physiological psychology (Vol. 1). New York: Academic Press, 1966. Pp. 210-272.

Mille R, N. E. Studies of fear as an acquirable drive: I. Fear as motivation and fear-reduction as reinforcement in the learning of new responses. Journal of Experimental Psychology, 1948, 38, 89-101.

Robinson, E. Effect of amygdalectomy on fear-motivated behavior in rats. Journal of Comparative and Physiological Psychology, 1963, 56, 814-820.

URETSKY, E., \& MCCLEARY, R. A. Effect of hippocampal isolation on retention. Journal of Comparative and Physiological Psychology, 1969, 68, 1-8.

URSIN, H. Effect of amygdaloid lesions on avoidance behavior and visual discrimination in cats. Experimental Neurology, 1965, 11, 298-317.

(Received for publication September 2, 1975.) 